\title{
FOLLOW-UP OF NEUROCYSTICERCOSIS PATIENTS AFTER TREATMENT USING AN ANTIGEN DETECTION ELISA
}

\author{
NGUEKAM*, ZOLI A.P.*, ONGOLO-ZOGO P.**, DORNY P.***, BRANDT J.*** \& GEERTS S.***
}

\section{Summary :}

Seven patients with active neurocysticercosis (NCC) received an eight days treatment with albendazole and were followed up using computed tomography (CT-scan) and a monoclonal antibody based ELISA for the detection of circulating antigen (Ag-ELISA). Only three patients were cured as was shown by CT-scan and by the disappearance of circulating antigens one month after treatment. After a second course of albendazole therapy, two other patients became seronegative. CT-scan showed the disappearance of viable cysts in all persons who became seronegative whereas patients who were not cured remained seropositive. These preliminary results show that this AgELISA is a promising technique for monitoring the success of treatment of NCC patients because of the excellent correlation between the presence of circulating antigens and of viable brain cysts.

KEY WORDS : Taenia solium, CT-scan, ELISA, circulating antigen, neurocysticercosis, albendazole.

N eurocysticercosis (NCC) is an infection of the central nervous system by the larval stage of Taenia solium. It is recognized as a common cause of neurological disease in developing countries (Schantz et al., 1998). The presence of T. solium metacestodes in the nervous system leads to a variety of clinical manifestations depending upon the number, size, viability and location within the brain and the host inflammatory reaction (White, 2000). Albendazole and praziquantel are the drugs of choice for the treatment of NCC. Follow-up after treatment is usually done using computed tomography (CT-scan), which is an expensive technique for the people of developing countries (Tsang \& Wilson, 1995). Considering the importance of NCC and the increasing poverty in these countries, it is necessary to investigate alternative techniques, which could reduce at least the cost of evaluation of the efficacy of the treatment. Since an antigen detection ELISA (Ag-ELISA) has been deve-

\footnotetext{
* University of Dschang, P.O. Box 96 Dschang, Cameroon.

** Central Hospital of Yaoundé, Department of Radiology, Yaoundé, Cameroon.

*** Institute of Tropical Medicine, Nationalestraat, Antwerp, Belgium. Correspondence: Stanny Geerts, Institute of Tropical Medicine, Nationalestraat 155, B-2000 Antwerp. E-mail: sgeerts@itg.be
}

Résumé : SUIVI de PATIENTS ATTEINTS DE NeUROCyStiCERCOSE APRÈS TRATTEMENT EN UTILISANT UN TEST ELISA POUR LA DÉTECTION D'ANTIGĖNES

Sept patients atteints de neurocysticercose active (NCC) ont été traités à l'albendazole pendant huit jours et ont été suivis en utilisant la tomodensitométrie et un ELISA pour la détection d'antigènes circulants à base d'anticorps monoclonaux (Ag-ELISA). Seulement trois patients étaient guéris comme indiqué par le CTscan et par la disparition des antigènes circulants un mois après traitement. Après un deuxième traitement à l'albendazole, deux autres patients sont devenus séronégatifs. Le CT-scan montrait la disparition de tous les cysticerques vivants chez les personnes qui étaient devenus séronégatifs, tandis que les patients qui n'étaient pas guéris restaient séropositifs. Ces résultats préliminaires montrent que I'Ag-ELISA est une technique prometteuse pour évaluer le succès d'un traitement de la neurocysticercose en raison de la corrélation excellente entre l'Ag-ELISA et la tomodensitométrie.

MOTS CLÉS : Taenia solium, tomodensitométrie, ELISA, antigène circulant, neurocysticercose, albendazole.

loped, which has a high sensitivity for the detection of human cysticercosis (Erhart et al., 2002) and which allows to distinguish cattle and pigs carrying living cysts from those harbouring only dead cysts (Brandt et al., 1992; Nguekam et al., in press), it was decided to evaluate its use in NCC patients. The purpose of this study was to compare the Ag-ELISA test with CTscan to evaluate the efficacy of an albendazole treatment of NCC.

\section{MATERIALS AND METHODS}

\section{PATIENTS}

S even patients with active lesions of NCC from the West province of Cameroon identified by serology (Ag-ELISA) and confirmed by brain CT-scan (in Yaounde Central Hospital) were included in this study. NCC was asymptomatic in all but two of them, who were epileptics (Batoula 94 and KE). Five of them were women and two men. Their age ranged between seven and 73 years (with a mean of $39.9 \pm 24.9$ years). The patients harboured an average of five viable cysts (range: 1 to 12 ) and of 7.6 calcified cysts (range: 0 to 25 ) in the 
brain. The localisation of the cysticerci was parenchymal and/or subarachnoidal. Informed consent was obtained from each adult and from the parents of the two young girls (seven and 15 years old) included in the study.

\section{TREATMENT PROTOCOL}

The patients were treated with albendazole (Alben ${ }^{\circledR}$ $400 \mathrm{mg}$, Smithkline Beecham) at a dosage of $15 \mathrm{mg} / \mathrm{kg}$ body weight/day for eight days as described by Del Brutto et al. (1999). To prevent adverse reactions, prednisolone (Solupred ${ }^{\circledR} 5 \mathrm{mg}$, Laboratoire Houdé) at $10 \mathrm{mg}$ per person thrice a day was given from one day prior to the albendazole treatment until at least four days after the end of it (Groll, 1982). The two epileptic patients continued to receive anti-epileptic treatment $\left(\right.$ Gardenal $\left.{ }^{\circledR}\right)$.

Six to nine months after the end of the first treatment, the patients who remained seropositive were treated again with the same dose of albendazole for a period of one month. In one patient (KE) the first treatment was not a course of eight days, but of one month.

\section{ANTIGEN DETECTION ELISA FOR CYSTICERCOSIS (AG-ELISA)}

The patients were sampled before the beginning of the treatment, one and three months after the first treatment and in those patients who received a second treatment, one month later. The serum samples were tested using a monoclonal antibody based antigen detection ELISA as described by Brandt et al. (1992) but slightly modified according to Pouedet et al. (2002). The sera were pre-treated using trichloroacetic acid and used in ELISA at a final dilution of $1 / 4$. Two monoclonal antibodies (MoAb) were used in a sandwich ELISA. MoAb B158C11A10 was used for coating and a biotinylated MoAb B60H8A4 was included as detector antibody. Orthophenylene diamine and $\mathrm{H}_{2} \mathrm{O}_{2}$ were used as chromogen-substrate solution. After arresting the reaction with $4 \mathrm{~N} \mathrm{H}_{2} \mathrm{SO}_{4}$ the plates were read using an ELISA reader (Labsystem Multiskan RC) at $492 \mathrm{~nm}$.
Eight negative reference control sera from local people of the region of Dschang (without any history of taeniasis or cysticercosis in the family) and one reference positive serum from a Cameroonian patient with confirmed cysticercosis (by CT-scan) were included in each ELISA run. The optical density (OD) of each serum sample was compared with the mean of the eight negative reference sera at a probability level of $P=0.001$ to determine the result using a modified Student test (Sokal \& Rohlf, 1981). The ELISA values were expressed as a ratio by dividing the OD of the test sample by the OD of the cut-off value. An ELISA ratio $>1$ was considered as positive.

\section{CT-SCAN OF THE BRAIN}

The CT-scans were performed in Yaounde Central Hospital using a Somatom AR STAR scanner (Siemens Medical Systems, Erlangen, Germany) before and after contrast fluid injection (Telebrix ${ }^{\circledR} 35$, Guerbet, France). Brain image slices of five $\mathrm{mm}$ thickness were transferred on negatives and scan reports were produced, indicating the number and types of lesions compatible to NCC. Two CT-scans were made for each patient: one before and one after treatment. For the group of patients who became seronegative after the first treatment, CT-scan was performed six to ten months later, whereas the patients, who received a second treatment, were scanned three to five months later. The radiologist was not aware of the serological results of the patients.

\section{RESULTS}

The serological results and brain CT-scan status of each patient before and after albendazole therapy are presented in Table I and Figures 1 and 2.

\section{Ag-ELISA RESULTS}

One month after the end of the first course of albendazole three patients became negative in the Ag-ELISA

\begin{tabular}{|c|c|c|c|c|c|}
\hline \multicolumn{2}{|c|}{ Patients } & \multicolumn{2}{|c|}{ Before treatment } & \multicolumn{2}{|c|}{ After treatment } \\
\hline \multicolumn{2}{|c|}{ Sex/age/epileptic status } & $\begin{array}{c}\text { CT-scan } \\
\text { no. liv/no. calc }\end{array}$ & ELISA ratio & $\begin{array}{c}\text { CT-scan } \\
\text { no. liv/no. calc }\end{array}$ & ELISA ratio \\
\hline- BL 21 & $\mathrm{M} / 73 / \mathrm{N}$ & $1 / 1$ & 1.8 & $0 / 1$ & $0.7^{*}$ \\
\hline - Baleo 01 & $\mathrm{~F} / 07 / \mathrm{N}$ & $2 / 0$ & 1.9 & $0 / 0$ & 0.8 \\
\hline - BFKP 137 & $\mathrm{M} / 60 / \mathrm{N}$ & $3 / 0$ & 1.3 & $0 / 0$ & 0.6 \\
\hline - BMKP 194 & $\mathrm{~F} / 60 / \mathrm{N}$ & $1 / 6$ & 11.5 & $0 / 3$ & $0.8^{*}$ \\
\hline - Batoula 94 & $\mathrm{~F} / 32 / \mathrm{E}$ & $6 \% / 25$ & 48.7 & $2 / 25$ & $20.6^{*}$ \\
\hline - Metchou 378 & $\mathrm{~F} / 15 / \mathrm{N}$ & $12 \%$ & 12.5 & $0 / 12$ & 0.7 \\
\hline$-\mathrm{KE}$ & $\mathrm{F} / 32 / \mathrm{E}$ & $10 / 15$ & 11.0 & $4^{\circ} / 15$ & 18.9 \\
\hline
\end{tabular}

\footnotetext{
*: after a second treatment; ${ }^{\circ}$ : including ring enhanced cysts; M: male; F: female; E: epilepsy; N: no epilepsy.
}

Table I. - Ag-Elisa and CT-scan results before and after treatment with albendazole of patients with neurocysticercosis. 


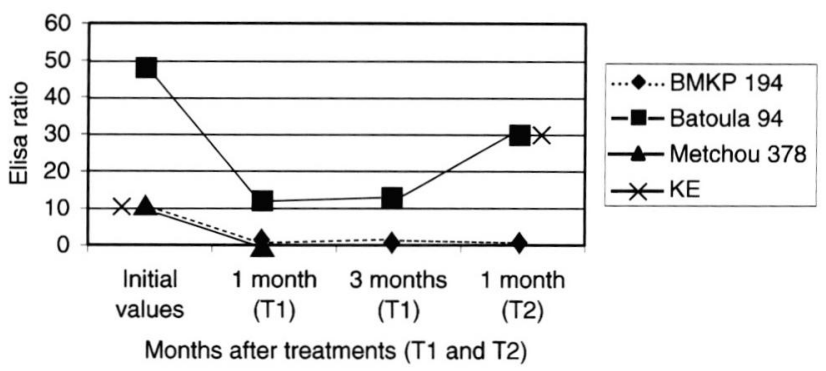

Fig. 1. - Antigen monitoring results in active NCC patients (initial Elisa ratio $>10$ ).

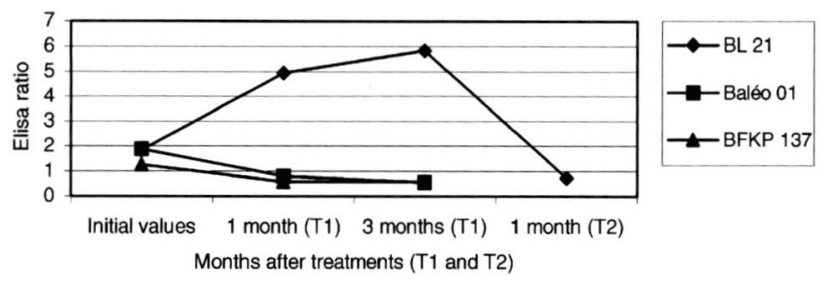

Fig. 2. - Antigen monitoring results in active NCC patients (initial Elisa ratio $<10$ )

(Table I). Patient (KE) received only one treatment course during one month and remained seropositive one month after therapy. A second Ag-ELISA performed on serum samples taken three months post treatment did not show any additional seronegative patients (Figs 1,2). One month after a second treatment of the three patients, who were not cured, two of them (BL 21 and BMKP 194) became seronegative.

\section{CT-SCAN RESULTS}

CT-scan of the brain after one or two courses of albendazole therapy showed that viable cysts had completely disappeared in five out of seven $(71.4 \%)$ patients. In the two others, either a reduction of the number of viable cysts (Batoula 94) or the presence of ring enhanced cysts indicating a process of degeneration (KE) was observed after treatment (Table I). In all patients where the viable cysts disappeared after treatment a negative ELISA result (ratio $<1$ ) was obtained whereas a persistence of even few living or degenerating cysts resulted in positive ELISA values.

\section{COMPARATIVE COSTS OF Elisa \\ AND CT-SCAN TECHNIQUES IN THE FOLLOW-UP OF NCC PATIENTS AFTER TREATMENT}

Up to now, CT-scan in Cameroon can only be carried out in Yaoundé or Douala. Besides the costs of scanning and the contrast agent, the total cost of a scan includes therefore also the travel and food expenses (for two days). This cost was estimated for each patient involved in the present study to approximately $152.2 €$ $(100,000$ CFA) whereas the cost of a test of an Ag-
ELISA (for 40 samples or one plate) was about $17 €$, i.e. $0.425 €$ per patient. The salaries of the medical doctor or the laboratory technicians are not included in this calculation.

\section{DISCUSSION}

C omputed tomography is an useful imaging technique for the diagnosis of human neurocysticercosis and the assessment of the efficacy of anthelminthic drugs in the treatment of this disease (Padma et al., 1994; Garcia et al., 1997; White, 2000). Its high cost, however, and the fact that it is often unavailable in rural regions of developing countries, where the prevalence of NCC is high (Tsang \& Wilson, 1995), constitute a limitation for its wide use. In this study, we compared this technique with an Ag-ELISA as an alternative method for the follow-up of neurocysticercosis patients after cysticidal treatment. The Ag-ELISA has been shown to detect the excretory-secretory products of viable cysticerci in cattle (Brandt et al., 1992), pigs (Nguekam et al., in press) and man (Erhart et al., 2002). These latter authors reported a sensitivity of $94.4 \%$ and the absence of cross-reactions with sera from human patients infected with Schistosoma, hydatid cysts, Ascaris, Trichuris, filaria, Entamoeba, Plasmodium and Trypanosoma.

Although the follow-up period was not the same for the two techniques, the results obtained in this study were very promising. There was $100 \%$ agreement between the CT-scan and the Ag-ELISA results. The five patients, who became seronegative one month after one or two albendazole courses, showed a complete disappearance of the viable cysts in the brain whereas the two remaining seropositive patients (Batoula 94 and KE) showed respectively two living cysts and four cysts with ring enhancement.

The sensitivity of our Ag-ELISA was better than that of another monoclonal antibody-based Elisa used by Garcia et al. (2000) in monitoring neurocysticercosis patients after treatment. This latter Ag-ELISA could not detect patients with only one viable cyst and/or enhancing lesion whereas in this study two patients with one single living cysticercus in the brain could be identified.

These preliminary results clearly show that this monoclonal antibody-based Ag-ELISA is a promising technique to monitor neurocysticercosis patients after treatment. In addition, it is much cheaper than CT-scan in particular for patients of developing countries where poverty is an increasing reality. Currently, studies on a larger number of NCC patients are going on in order to validate the Ag-ELISA as an alternative for CTscan. 


\section{ACKNOWLEDGEMENTS}

T This study was carried out with the financial support of the Belgian Directorate General for International Cooperation (DGIC, Brussels) and of the University of Dschang. The research was done within the framework agreement between DGIC and the Institute of Tropical Medicine, Antwerp.

\section{REFERENCES}

Brandt J.R.A., Geerts S., De Deken R., Kumar V., Ceulemans F., BriJs L. \& FALLA N. A monoclonal antibody-based ELISA for the detection of circulating excretory-secretory antigens in Taenia saginata cysticercosis. International Journal for Parasitology, 1992, 22, 471-477.

Del Brutto O.H., Campos X., Sanchez J. \& Mosquera A. Single-day praziquantel versus 1-week albendazole for neurocysticercosis. Neurology, 1999, 52, 1079-1091.

Erhart A., Dorny P., Nguyen Van De, Ha Viet Vien, Dang Cam Thach, Nguyen Duy Toan, Le Dinh Cong, Geerts S., Speybroeck N., Berkvens D. \& Brandt J. Taenia solium cysticercosis in a village in Northern Viet Nam: Sero-prevalence study using an ELISA for detecting circulating antigen. Transactions of the Royal Society of Tropical Medicine and Hygiene, 2002, 96, 270-272.

Garcia H.H., Gilman R.H., Horton J., Martinez M., Herrera G., Altamirano J., Cuba J.M., Rios-Saavedra N., Verastegui M., Botero J., Gonzalez A.E. \& the cysticercosis Working Group in Peru. Albendazole therapy for neurocysticercosis: A prospective double-blind trial comparing 7 versus 14 days of treatment. Neurology, 1997 48, 14211427.

Garcia H.H., Parkhouse R.M.E., Gilman R.H., Montenegro T., Bernal T., Martinez S.M., Gonzalez A.E., Tsang V.C.W. \& HARRISON L.J.S. Serum antigen detection in the diagnosis, treatment, and follow- up of neurocysticercosis patients. Transactions of the Royal Society of Tropical Medicine and Hygiene, 2000 94, 673-676.

Groll E.W. Chemotherapy of human cysticercosis with praziquantel. In: Flisser. Cysticercosis: present state of knowledge and perspectives. Academic Press, New York, 1982, 207-218.

Nguekam, Zoli A.P., Vondou L., Pouedet S.M.R., Assana E., DORNY P., BRANDT J. \& GEERTS S. Kinetics of circulating antigens in pigs experimentally infected with Taenia solium eggs. Veterinary Parasitology, 2003 (in press).

Padma M.V., Behari M., Misra N.K. \& Ahuja G.K. Albendazole in single CT ring lesions in epilepsy. Neurology, 1994, 44, 1344-1346.

Pouedet M.S.R., Zoli A.P., Nguekam, Vondou L., Assana E., Speybroeck N., Berkvens D., Dorny P., Brandt J. \& Geerts S. Epidemiological survey of swine cysticercosis in two rural communities of West Cameroon. Veterinary Parasitology, 2002, 106, 45-54.

SChantz P.M., Wilkins P.P. \& Tsang V.C.W. Immigrants, imaging, and immunoblots: the emergence of neurocysticer- cosis as a significant public health problem. In: Scheld W.M., Craig W.A. and Hughes J.M. Emerging Infections 2. ASM Press, Washington, D.C., 1998, 213-242.

SOKAL R.S. \& ROHLF J.J. Biometry: the principles and practice of statistics in biological research, $2^{\text {nd }}$ ed. Freeman, New York, 1981, 895 p.

Sotelo J. Treatment of brain cysticercosis. Surgical Neuro$\log y, 1997,48,110-112$.

TSAng V.C.W. \& Wilson M. Taenia solium cysticercosis: an under-recognized but serious public health problem. Parasitology Today, 1995, 11, 124-126.

White C.A. Jr. Neurocysticercosis: updates on epidemiology, pathogenesis, diagnosis, and management. Annual Review of Medicine, 2000, 51, 187-206.

Reçu le 7 septembre 2002 Accepté le 15 novembre 2002 